\title{
Antenna-Coupled Titanium Microbolometers: Application for Precise Control of Radiation Patterns in Terahertz Time-Domain Systems
}

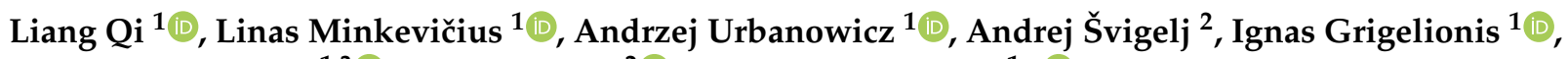 \\ Irmantas Kašalynas ${ }^{1,3}\left(\mathbb{D}\right.$, Janez Trontelj ${ }^{2} \mathbb{D}$ and Gintaras Valušis ${ }^{1, *(\mathbb{D})}$ \\ 1 Center for Physical Sciences and Technology (FTMC), Department of Optoelectronics, Sauletekio Ave. 3, \\ LT-10257 Vilnius, Lithuania; liang.qi@ftmc.lt (L.Q.); linas.minkevicius@ftmc.lt (L.M.); \\ andzej.urbanovic@ftmc.lt (A.U.); ignas.grigelionis@ftmc.lt (I.G.); irmantas.kasalynas@ftmc.lt (I.K.) \\ 2 Laboratory for Microelectronics, Faculty of Electrical Engineering, University of Ljubljana, Tržaška 25, \\ 1000 Ljubljana, Slovenia; andrej.svigelj@fe.uni-lj.si (A.Š.); janez.trontelj@fe.uni-lj.si (J.T.) \\ 3 Luvitera Ltd., Savanoriu Ave. 235, LT-02300 Vilnius, Lithuania \\ * Correspondence: gintaras.valusis@ftmc.lt
}

Citation: Qi, L.; Minkevičius, L.; Urbanowicz, A.; Švigelj, A.; Grigelionis, I.; Kašalynas, I.; Trontelj, J.; Valušis, G. Antenna-Coupled Titanium Microbolometers: Application for Precise Control of Radiation Patterns in Terahertz Time-Domain Systems. Sensors 2021, 21,3510. https://doi.org/10.3390/ s21103510

Academic Editor: Bernhard Wilhelm Roth

Received: 16 April 2021

Accepted: 14 May 2021

Published: 18 May 2021

Publisher's Note: MDPI stays neutral with regard to jurisdictional claims in published maps and institutional affiliations.

Copyright: (c) 2021 by the authors. Licensee MDPI, Basel, Switzerland. This article is an open access article distributed under the terms and conditions of the Creative Commons Attribution (CC BY) license (https:// creativecommons.org/licenses/by/ $4.0 /)$.

\begin{abstract}
An ability of lensless titanium-based antenna coupled microbolometers (Ti- $\mu$ bolometers) operating at room temperature to monitor precisely radiation patterns in terahertz time-domain spectroscopy (THz-TDS) systems are demonstrated. To provide comprehensive picture, two different THz-TDS systems and Ti- $\mu$ bolometers coupled with three different antennas-narrowband dipole antennas for $0.3 \mathrm{THz}, 0.7 \mathrm{THz}$ and a log-periodic antenna for wideband detection-were selected for experiments. Radiation patterns, spatial beam profiles and explicit beam evolution along the propagation axis are investigated; polarization-sensitive properties under various $\mathrm{THz}$ emitter power ranges are revealed. It was found that the studied Ti- $\mu$ bolometers are convenient lensless sensors suitable to discriminate and control $\mathrm{THz}$ radiation pattern features in various wideband THz-TDS systems.
\end{abstract}

Keywords: titanium-based microbolometeric sensors; THz time-domain spectroscopy systems; precise $\mathrm{THz}$ mode control; radiation pattern monitoring

\section{Introduction}

Terahertz time-domain spectroscopy (THz-TDS) is a distinctive example of a wideband electromagnetic radiation system invented more than three decades ago [1]. The $\mathrm{THz}$ spectroscopy is very powerful technique for the test and discrimination of different kind of materials [2-4]; it can successfully serve for a medical inspection [5,6], security aims [7,8], photovoltaics industry $[9,10]$ as well as food control purposes [11,12].

From the point of view of $\mathrm{THz}$ imaging, it displays a possibility for multispectral (colored) THz imaging enabling thus discrimination of different materials without recording their spectral signatures directly [13-15] as "colored" images of the THz light contain information on chemical composition, spatial distributions and physical properties of tested objects. One needs to note that the quality of obtained images are highly sensitive to the radiation pattern of scanning beam [16]. This circumstance becomes of a particular importance in real-time inspection and sensing when a high capture rate of images is required, and detectors arrays need to be implemented in the recording set-up using collimated beams. Moreover, even in the case of bulky objects imaging, when extended focus [17] or bifocal (Fibonacci) focusing [18] helps to discriminate the content, control and monitoring of the beam shape along its propagation axis demands of special attention.

High quality images of optoelectronically generated radiation patterns covering $0.1-2 \mathrm{THz}$ range were recorded by room-temperature antenna-coupled $\alpha$-silicon-based 
microbolometers array with integrated CMOS read-out electronics [19]. Thin film vanadium oxide (VOx)-based microbolometers arrays were demonstrated as promising tool for label-free detection of reaction of small molecules with proteins [20]. Titanium-based microbolometers (Ti- $\mu$ bolometers) were found to be useful and convenient instrument in security [21], plastic package inspection and spectroscopic-spatial analysis of materials proving the maturity of $\mathrm{THz}$ technology for medicine applications [22].

Very recently, we have demonstrated that optimised room temperature Ti- $\mu$ bolometers can serve as a convenient and easy-to-use imaging tool to accurately adjust low power $\mathrm{THz}$ sources without additional focusing components [23]. Radiation patterns and spatial modes profiles generated by electronic sources, frequency domain spectrometers, optically pumped molecular THz laser were measured and analyzed [23]. In addition, it was shown that these devices exhibiting room temperature sensitivity values of $200 \mathrm{kV} / \mathrm{W}$, noiseequivalent power (NEP) of $20 \mathrm{pW} / \sqrt{\mathrm{Hz}}$, and the response time in the $5 \mu$ s range are sensitive and fast enough to monitor precisely coherent $\mathrm{THz}$ emitters in optoelectronic time-domain systems.

In this work, we present comprehensive experimental study dedicated to reveal features of Ti- $\mu$ bolometers for spatial mode control in THz TDS systems. Three lensless Ti- $\mu$ bolometer sensors with different antenna designs-narrowband dipole antenna for $0.3 \mathrm{THz}, 0.7 \mathrm{THz}$ and a log-periodic antenna for wideband detection-are explored in detail. Radiation patterns, spatial beam profiles and explicit beam evolution along the propagation axis was examined, polarization sensitive properties were revealed under different $\mathrm{THz}$ emitter power range. It was shown that the Ti- $\mu$ bolometers do not require additional focusing optics to discriminate spatial mode features in the wideband $\mathrm{THz}$ pulse. It was revealed that Ti- $\mu$ bolometer sensors and their arrays can be employed as easy-to-use imaging instruments in THz TDS systems for accurate optical alignment and quality control of their radiation patterns.

\section{Materials and Methods}

\subsection{Design and Spectral Characterization of Ti- $\mu$ bolometer Sensors}

The design of antenna-coupled Ti- $\mu$ bolometers and their frequency properties are presented in Figure 1. Each microbolometer was fabricated from titanium which was found to be the most suitable for silicon processing technology, temperature coefficient and reliability. The titanium bridge of $12 \mu \mathrm{m}$ and $2 \mu \mathrm{m}$ in length and width respectively was electrodeposited on the silicon nitride (SiN) membrane of thickness of $2 \mu \mathrm{m}$. The aluminum antenna and interconnection paths of area of approximately $500 \mu \mathrm{m} \times 500 \mu \mathrm{m}$, were formed around the active part of Ti- $\mu$ bolometer (see in top of the panel (a) in Figure 1). To reduce the heat capacitance and to increase the speed of operation, the Ti- $\mu$ bolometer was suspended in the air by etching out the underlying $\mathrm{SiN}$ membrane and was coupled either to resonant double-dipole or to wideband log-periodic type $\mathrm{THz}$ antenna (see panel (a) in Figure 1) [22-24]. Sensitivity of the device was enhanced resonantly by adjustment of a dipole antenna and resonant-cavity design: the back side reflection mirror was placed at the quarter wavelength distance (Figure 1a).

The active gain of each antenna was numerically simulated and is shown in Figure $1 \mathrm{~b}$. Detectors' response spectra at room temperature were also characterized experimentally employing a custom-made Fourier spectrometer. The reference spectrum was registered when interferometer was coupled with a thermo-acoustic Golay cell detector featuring the flat response in $\mathrm{THz}$ frequency range. Finally, in order to avoid the influence of emitter and the beamsplitter spectral response the bolometer detected spectrum was divided by the reference spectrum detected by the Golay cell. As it can be seen from the normalized response spectra given in Figure 1c, the resonant Ti- $\mu$ bolometers designed for $0.3 \mathrm{THz}$ and $0.7 \mathrm{THz}$ show the detection peaks around the frequencies of $0.3 \mathrm{THz}$ and $0.65 \mathrm{THz}$, respectively. Additionally, at higher frequencies, lobes exhibiting lower amplitudes are observed which most probably come from higher dipole antenna resonances. The detector with log-periodic antenna demonstrates detection bandwidth in the range of $0.25-1.3 \mathrm{THz}$ 
(Figure $1 \mathrm{~b}$ ). As is visible from Figure $1 \mathrm{c}, \mathrm{b}$, the obtained experimental data correlate well with the theoretical predictions.

The sensitivity and NEP values are given in Table 1 . Additionally, here the geometrical bolometer antennae parameters such as length $L$, width $W$ and polar angle $\phi$ of antenna fingers of the wideband detector are tabulated.

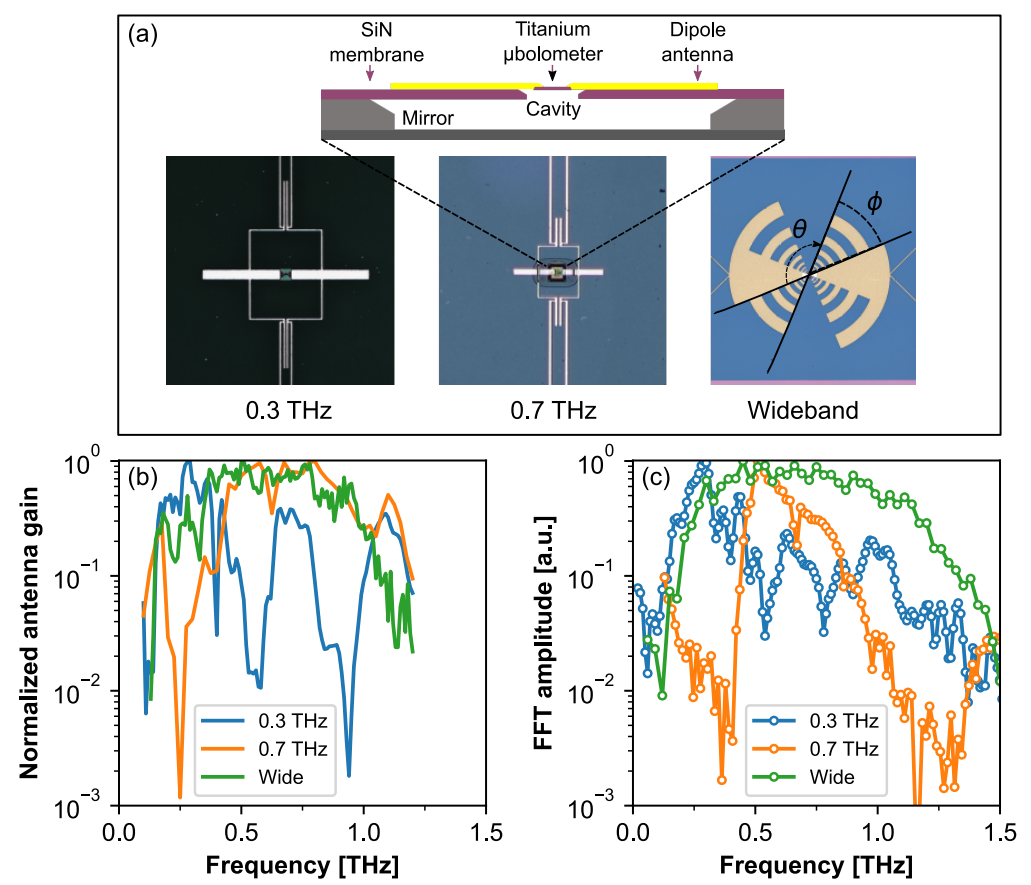

Figure 1. The design and response spectra of antenna-coupled Ti- $\mu$ bolometers. Top panel (a): The design and schematic cross-section of the Ti- $\mu$ bolometer coupled with different antennas for $0.3 \mathrm{THz}, 0.7 \mathrm{THz}$ and for wideband detection (from left to right). Digital photos show top views of Ti- $\mu$ bolometer detectors coupled with dipole antenna design. The geometry of the titanium bridge amounts to $12 \mu \mathrm{m}$ length and $2 \mu \mathrm{m}$ width. The angles $\theta$ and $\phi$ in photo of the wideband detector are defined as sample rotation angle for polarization measurements and the polar angle of antenna fingers, respectively. The design is adapted from Refs. [22,23]. Panel (b): Simulated spectra of the normalized antenna gain for the different antenna's designs. Panel (c): Response spectra of the devices were measured using Fourier transform far-infrared spectrometer as described in Ref. [22].

Table 1. The main performance and antenna geometrical parameters of the resonant $(0.3 \mathrm{THz}$ and $0.7 \mathrm{THz}$ ) and the wideband detectors. Note the same NEP for both resonant antenna-coupled devices. Presented sensitivity values are of Ti- $\mu$ bolometer itself, without electronics.

\begin{tabular}{llllll}
\hline Detector Type & $\begin{array}{l}\text { Sensitivity } \\
{[\mathbf{V} / \mathbf{W}]}\end{array}$ & $\begin{array}{l}\mathbf{N E P} \\
{[\mathbf{p W} / \sqrt{\mathbf{H z}}]}\end{array}$ & $\boldsymbol{L}[\boldsymbol{\mu \mathrm { m } ]}$ & $\boldsymbol{W}[\boldsymbol{\mu \mathrm { m }}]$ & $\boldsymbol{\phi}[\mathbf{d e g}]$ \\
\hline $0.3 \mathrm{THz}$ & 1000 & 20 & 674 & 16 & - \\
$0.7 \mathrm{THz}$ & 1000 & 20 & 247 & 39 & - \\
Wideband & 50 & 60 & 1042 & - & 45 \\
\hline
\end{tabular}

\subsection{Experimental Setup of THz Time-Domain System}

The optical outputs of two different THz-TDS systems without reference beams schematically shown in the upper parts of Figure $2 \mathrm{a}, \mathrm{b}$ were characterized using three different Ti- $\mu$ bolometer designs described above.

In THz-TDS System 1, a femtosecond fiber laser (Femtofiber Pro, Toptica Photonics $\mathrm{Ag}$, Munich, Germany) providing pulses of $780 \mathrm{~nm}$ wavelength, $90 \mathrm{fs}$ pulse duration and $150 \mathrm{~mW}$ output power at $80 \mathrm{MHz}$ pulse repetition rate was used to excite photoconductive antenna made from $350 \mu \mathrm{m}$-thick LT-GaAs wafer. A THz emitter antenna (Teravil Ltd., 
Vilnius, Lithuania) had the shape of a H-dipole made from Ti/Au with the width of $20 \mu \mathrm{m}$ and the gap of $50 \mu \mathrm{m}$ between electrodes. A $8 \mathrm{~mm}$-thick and $12 \mathrm{~mm}$ in diameter high resistivity hyperhemispherical silicon lens (Lens 1 ) with a focal distance of $500 \mu \mathrm{m}$ was used to collimate the $\mathrm{THz}$ radiation. A reference $\mathrm{THz}$ spectrum measured with $\mathrm{THz}$ detector (Teravil Ltd., Vilnius, Lithuania) is shown in the bottom of Figure 2a. THz detector was a Hertzian dipole type photoconductive antenna made from LT-GaAs with a $6 \mu \mathrm{m}$ width gap. The emitter exhibits a wide emission spectrum ranging from 0 to $5 \mathrm{THz}$, as it can be seen from the panel (a) in Figure 2.

In THz-TDS System 2, femtosecond fiber laser (LightWare FF50, Ekspla, Vilnius, Lithuania) with a center wavelength of $1064 \mathrm{~nm}, 150 \mathrm{fs}$ pulse duration, $60 \mathrm{~mW}$ output power and $30 \mathrm{MHz}$ repetition rate was employed. The source of $\mathrm{THz}$ radiation was a photoconductive emitter made from LT-GaAsBi (Teravil Ltd., Vilnius, Lithuania) wafer with thickness of $500 \mu \mathrm{m}$. For collimation, silicon hyperhemispherical lens (Lens 2) with the same specifications as in System 1 was used. A THz emitter/detector antenna was the $\mathrm{H}$-dipole made of $\mathrm{Ti} / \mathrm{Au}$ with dipole antenna gap size of $6 \mu \mathrm{m}$. The reference $\mathrm{THz}$ spectrum measured with $\mathrm{THz}$ detector (Teravil Ltd., Vilnius, Lithuania) is given in the Figure $2 \mathrm{~b}$. It is seen that it extends up to nearly of $4 \mathrm{THz}$.
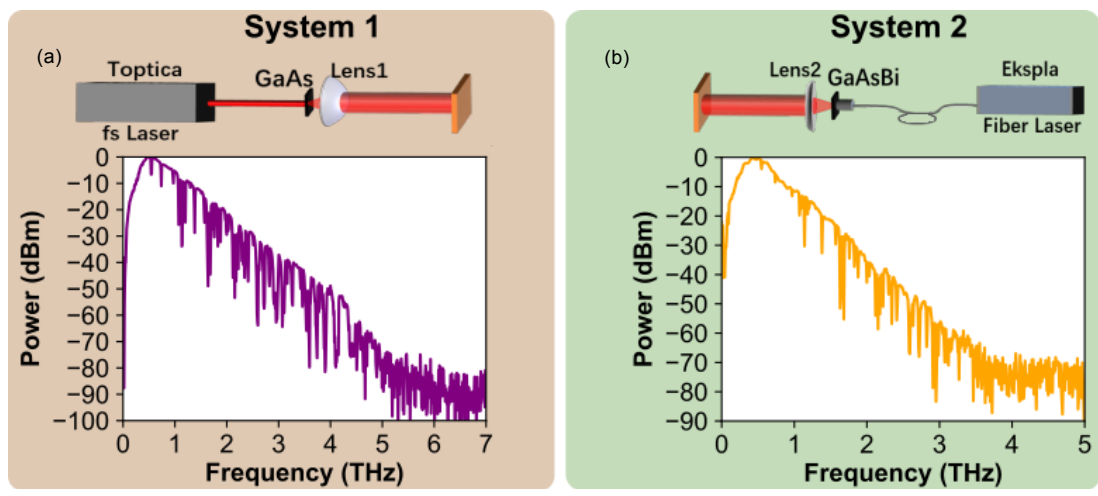

Figure 2. Schematics of THz TDS investigation set-ups and their emission spectra. System 1 (panel (a)) is based on femtosecond fiber laser (Femtofiber Pro, Femtofiber Pro, Toptica Photonics Ag, Munich, Germany) delivering pulses of $780 \mathrm{~nm}$ wavelength and $90 \mathrm{fs}$ pulse duration pulses to excite THz emission from photoconductive antenna made from LT-GaAs. System 2 (panel (b)) consists of femtosecond fiber laser (LightWare FF50, Ekspla, Vilnius, Lithuania) with a center wavelength of $1064 \mathrm{~nm}$ and $150 \mathrm{fs}$ pulse duration pulses employed to excite $\mathrm{THz}$ radiation from GaAsBi-based emitter. Please note that both $\mathrm{THz}$ spectra are decorated by sharp lines of absorption in water vapour.

The investigated Ti- $\mu$ bolometers were mounted on a 3-dimensional $x, y, z$ electric translation stage and mechanical rotation stage. The detector can be moved in the $x-y$ plane for a spatial mode profile detection; separately, a movement along $z$-axis enables testing the beam profile along the propagation direction. While dipole antenna equipped Ti- $\mu$ bolometers are sensitive to polarization, rotation with the $\theta-$ angle as shown in the (a) panel of Figure 1 allows studying $\mathrm{THz}$ beam polarization properties.

The signal of radiation emitted by TDS source was captured by the $\mu$ bolometer and was read out using the conventional lock-in technique. The reference was taken from a mechanical chopper modulating the femtosecond laser beam at $930 \mathrm{~Hz}$.

\section{Results and Discussion}

The radiation patterns of THz-TDS spectrometers were investigated via five diverse approaches. Initially, spatial modes profiles were examined in $x-y$ plane, i.e., perpendicular to the beam propagation direction within two distances-very close to the THz emitter, placing the Ti- $\mu$ bolometer at $10 \mathrm{~mm}$ from the source; then-recording it in a far-field, as far as $115 \mathrm{~mm}$ from the source. The next step was to explore spatial profile features along the propagation direction and to study polarization properties of the devices. Finally, 
collimating lenses were removed from the emission set-up aiming to illustrate abilities to resolve spatial modes of the emitter without any optical components. The scanning was performed moving the stage at continuous velocity of $25 \mathrm{~mm} / \mathrm{s}$ with the lock-in averaging constant of $20 \mathrm{~ms}$. The acquisition of $12 \mathrm{~mm}$ by $12 \mathrm{~mm}$ image took approximately $350 \mathrm{~s}$ for the given scanning velocity.

\subsection{Features of the Radiation Patterns}

The radiation patterns scanned in $x-y$ plane in the distance of $10 \mathrm{~mm}$ from the emitter lens tip using Ti- $\mu$ bolometers of three different antenna designs are depicted in Figure 3. The conventional femtosecond Ti-Sapphire system emitting wideband $\mathrm{THz}$ pulses in a frequency range of $0.1-2.5 \mathrm{THz}$ with an average power of $1.2 \mu \mathrm{W}$ served as a $\mathrm{THz}$ source. The emitter was based on $500 \mu \mathrm{m}$-thick LT-GaAs wafer, the lens parameters are the same as described above. As it can be seen, radiation patterns recorded with different antennacoupled Ti- $\mu$ bolometer exhibits different features: $0.3 \mathrm{THz}$ resonant Ti- $\mu$ bolometer displays the symmetric mode spot (Figure 3a), while distinctive feature of $0.7 \mathrm{THz}$ frequency sensors is strongly expressed side lobes in intensity distribution (Figure 3b). Spatial beam pattern registered by the wideband detector reveals a bright central spot accompanied by wellpronounced side lobes as presented in Figure 3c. The spatial evolution of wideband $\mathrm{THz}$ pulses along an optical axis is shown in Figure 3d-f. Results demonstrate that spatial features-enriched beam profile evolves into almost symmetric Gaussian beam at the distance of $50 \mathrm{~mm}$ from the lens. This illustrates nicely that the Ti- $\mu$ bolometer is quite convenient and sensitive enough to characterize the performance of THz-TDS emitter with the hyperhemispherical lens attached. The recorded pattern structure can be understood as follows: at low frequencies a wide central part is formed, while at higher frequencies the central pattern part becomes narrower [25]. Regarding side fringes, their origin is related to internal reflections in the lens, and are emitted in smaller angles (bend closer to the central beam part). Consequently, only the wide central beam part is registered with $0.3 \mathrm{THz}$ frequency sensor, while the $0.7 \mathrm{THz}$ and the wideband $\mu$ bolometers display the narrowed central part and fringes around it.
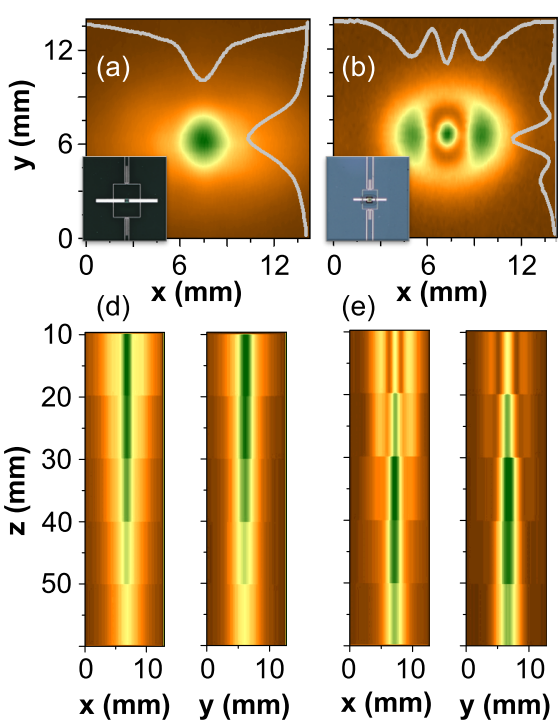

(e)
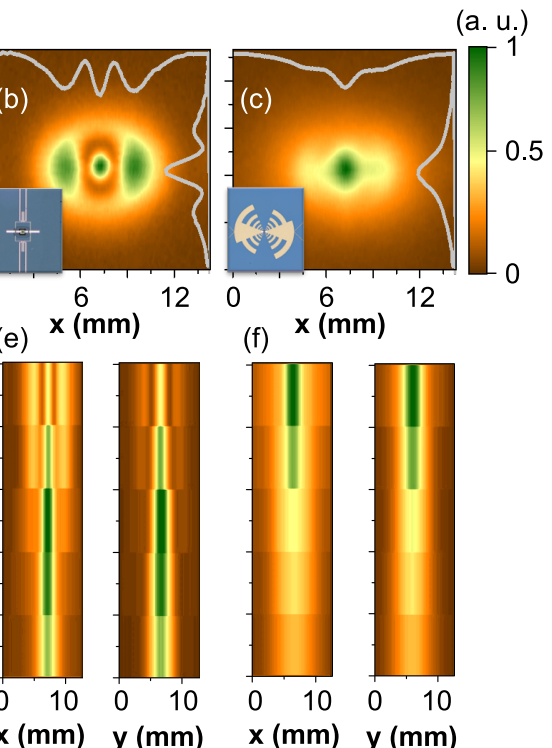

Figure 3. The radiation patterns measured with different Ti- $\mu$ bolometers placed at $z=10 \mathrm{~mm}$ position: Panel (a) $-0.3 \mathrm{THz} \mu$ bolometer; panel (b) $-0.7 \mathrm{THz}$ Ti- $\mu$ bolometer, panel (c) —wideband Ti- $\mu$ bolometer. Grey lines indicate intensity center cross-sections along the relevant axes. Note particular spatial mode profiles clearly resolved by different antenna-coupled Ti- $\mu$ bolometers. Panels (d-f) depict $x-z$ and $y-z$ scans from $10 \mathrm{~mm}$ to $50 \mathrm{~mm}$ along $z$ direction for $0.3 \mathrm{THz}, 0.7 \mathrm{THz}$ and wideband Ti- $\mu$ bolometers, respectively. 
A precise optical alignment of THz radiation in TDS spectrometer and monitoring of the beam pattern propagation can aid in improvement of system performance, e.g., by increasing its dynamical range and lowering the noise floor-features which are of particular importance for imaging and spectroscopy. Therefore, the Ti- $\mu$ bolometers were tested as possible instrument for these aims intending to provide full experimental characterization of $\mathrm{THz}$ beams evolution via amplitude distribution across the $\mathrm{THz}$ beam in a far-field varying the distance from $5 \mathrm{~cm}$ up to $12 \mathrm{~cm}$ range from the emitter.

The results of investigation for both THz TDS systems are given in Figure 4 starting at $75 \mathrm{~mm}$ and $55 \mathrm{~mm}$ distances, for System 1 and System 2, respectively. Such starting points were chosen according to the geometrical restrictions in investigated systems. The first feature that attracts attention is different beam spot sizes if compare starting recording data of System 1 and System 2-the beam spot is significantly smaller in the latter case. As was aforesaid, the hyperhemispherical lens of the same design was used to collimate the emitters beams profile. To do it effectively, one needs to place the emitter in its focal point. As the $\mathrm{THz}$ emitters in the experimental setups were of different thicknesses ( $350 \mu \mathrm{m}$ vs. $500 \mu \mathrm{m})$, the observed differences unveil that emitter thickness of the System 1 was not well matched to lens focal distance resulting thus into a larger divergence of the emitted beam mode.
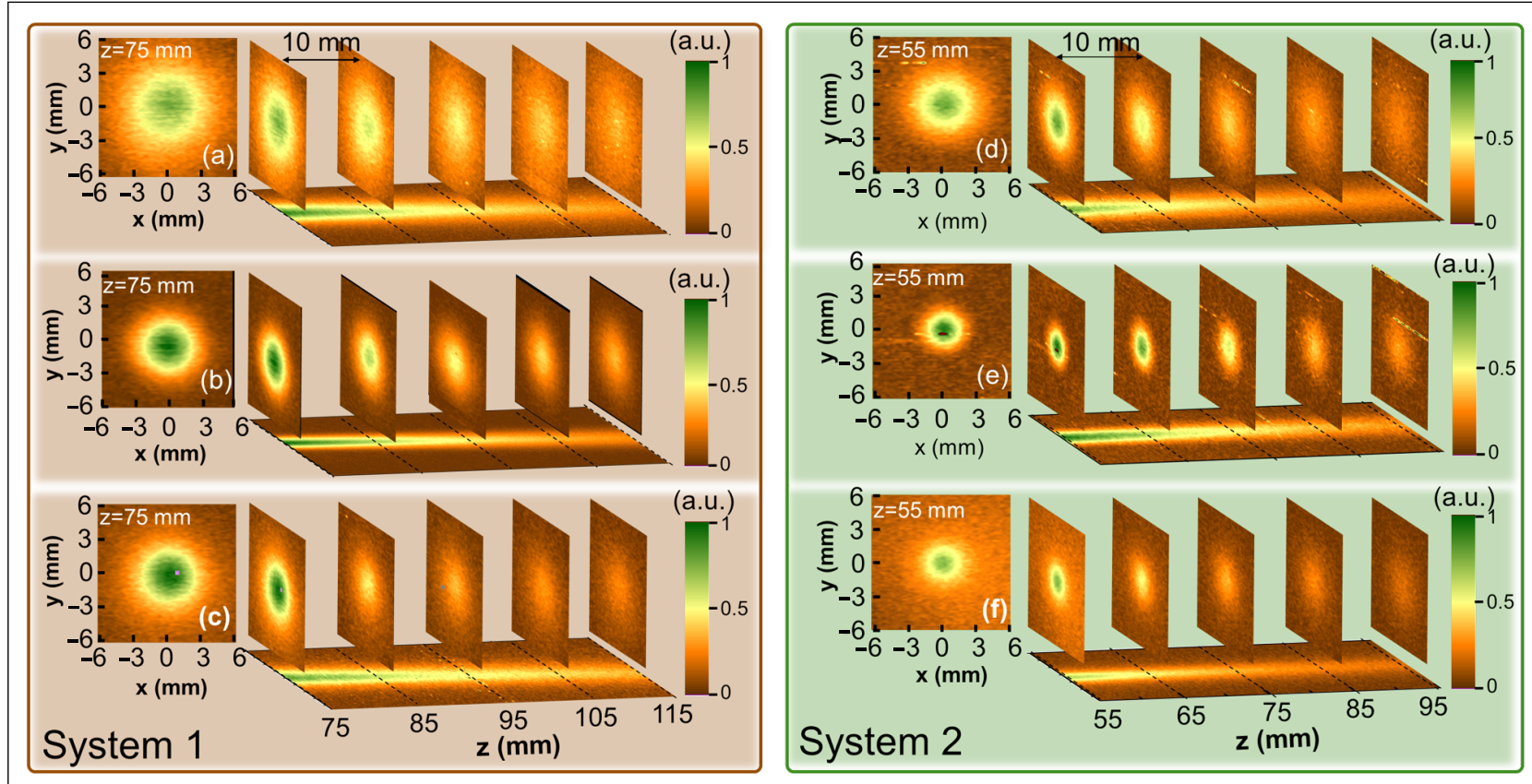

Figure 4. Radiation pattern distributions and beam evolution along the propagation axis recorded by antenna-coupled Ti- $\mu$ bolometers for two different THz-TDS systems. The signal is normalized to maximum values of the relevant plots. Left panels displays spatial mode profile at starting positions. Note different mode spatial diameter if compare both systems at the same distance from the lens tip. It stems from different thicknesses ( $350 \mu \mathrm{m}$ vs. $500 \mu \mathrm{m})$ of emitters used in experimental setups. As emitter thickness of System 1 was not well matched to the lens focal distance, it results to a larger divergence of the emitted mode profile. Beam pattern profile evolution was investigated in the range of $75 \mathrm{~mm}-115 \mathrm{~mm}$ and $55 \mathrm{~mm}-95 \mathrm{~mm}$ after the collimating lens in System 1 and System 2, respectively. Distances were selected according to mechanical limitations of geometrical dimensions of the used emitters and detectors. Five transverse mode profiles samples were recorded every $10 \mathrm{~mm}$ along $z$-direction for each TDS system. Panels $(\mathbf{a}-\mathbf{c})$-System 1; panels (d-f) —System 2. Panels $(\mathbf{a}, \mathbf{d})-0.3 \mathrm{THz}$; panels $(\mathbf{b}, \mathbf{e})-0.7 \mathrm{THz}$; panels $(\mathbf{c}, \mathbf{f})$ - wideband Ti- $\mu$ bolometer. Please note that the spatial profiles and beam propagation properties of both systems exhibit no essential differences.

The beam pattern evolution along the propagation axis illustrated via five $x-y$ crosssections of the mode profile registered every $10 \mathrm{~mm}$ is presented in Figure 4 . As it can be seen from Figure 4, the investigated pattern does not experience essential changes with 
the distance. Note highly expressed central part of pattern decaying with the distance and absence of side-lobes in this far-field experiment. The beam is also of small divergence which was estimated $\Theta \approx 0.045 \mathrm{rad}$ at $0.7 \mathrm{THz}$ in both experimental systems. Since $\Theta=\lambda / 2 \pi n \omega_{0}$, where $\lambda$ is a wavelength, $n$ denotes the refractive index and $\omega_{0}$ stands for a beam waist, we can easily find that $\omega_{0}=1.52 \mathrm{~mm}$ for the above given divergence and radiation frequency in System 2.

These experimental observations are in a good agreement with theoretically calculated beam patterns in the distances far from the lens tip [25]. However, one can underline the variation of the central spot diameter of the detected pattern with frequency in both $\mathrm{THz}$ TDS systems. The beam profile recorded with the sensor designed for $0.7 \mathrm{THz}$ frequency displays the smallest diameter $5.10 \mathrm{~mm}$ in System 1 versus $2.55 \mathrm{~mm}$ in System 2, the wideband Ti- $\mu$ bolometer-slightly larger beam diameter $7.95 \mathrm{~mm}$ vs $3.45 \mathrm{~mm}$, while the profile recorded with the antenna-coupled Ti- $\mu$ bolometer for $0.3 \mathrm{THz}$ amounts to $8.40 \mathrm{~mm}$ vs $4.95 \mathrm{~mm}$. The accuracy here is in the order of $0.15 \mathrm{~mm}$. As already mentioned earlier, the beam width at $0.3 \mathrm{THz}$ is the largest because of the longer wavelength and larger dipole antenna dimensions (see Table 1 ). The wideband Ti- $\mu$ bolometer results (Figure $4 \mathrm{c}, \mathrm{f}$ ) show the beam spot size which is close to that for $0.3 \mathrm{THz}$ in Figure $4 \mathrm{a}, \mathrm{d}$, but with higher intensity of the central part of the beam. Such increase in intensity is governed mainly by the Ti- $\mu$ bolometer's responsivity bandwidth (see Figure 1 ) and by the fact that the lens concentrates higher frequencies in wideband $\mathrm{THz}$ emission closer to the optical axis.

\subsection{Polarization Properties}

Features of the presented Ti- $\mu$ bolometer design enables it to be sensitive to the polarization of the $\mathrm{THz}$ radiation - if the sensor axis is aligned in parallel to the $\mathrm{THz}$ field electrical component of the incident light, i.e., $\theta=0 \mathrm{deg}$-the coupling should be efficient resulting therefore to the maximal heating of the $\mu$ bolometer's titanium bridge, and, as a consequence, to the largest signal. Gradual rotation around optical axis $(0 \leq \theta \leq 90 \mathrm{deg})$ can serve hence as polarization-resolved tool permitting using the Ti- $\mu$ bolometer to monitor polarization properties in $\mathrm{THz}$ TDS spectrometer.

Investigations were performed at distances $75 \mathrm{~mm}$ and $55 \mathrm{~mm}$ from the lens tip (front $x-y$ scan planes positions as given in Figure 4) in System 1 and System 2, respectively. The obtained polarization results for all the investigated $\mu$ bolometers are shown in Figure 5. To avoid possible misalignment artifacts, the angular dependencies of signal at the pattern center are normalized to the signal at $\theta=0$ deg and presented in panels (d) and (i) for different $\mathrm{THz}$ TDs spectrometers. As is seen, the dependencies decrease gradually with the rotation angle and flatten above 80 degrees, where the signal level approaches the noise floor.

One can indicate that an ellipticity of the beam spot and its smooth decrease down to the noise level is recorded by the Ti- $\mu$ bolometer along with $\theta$ change. This feature indicates that the sensor can be well-suited to monitor polarization state or cross-polarized angular emission patterns [26] of THz pulsed emission-it is rather important issue for the most of common real implementations of THz-TDS spectrometers or THz imaging systems. 


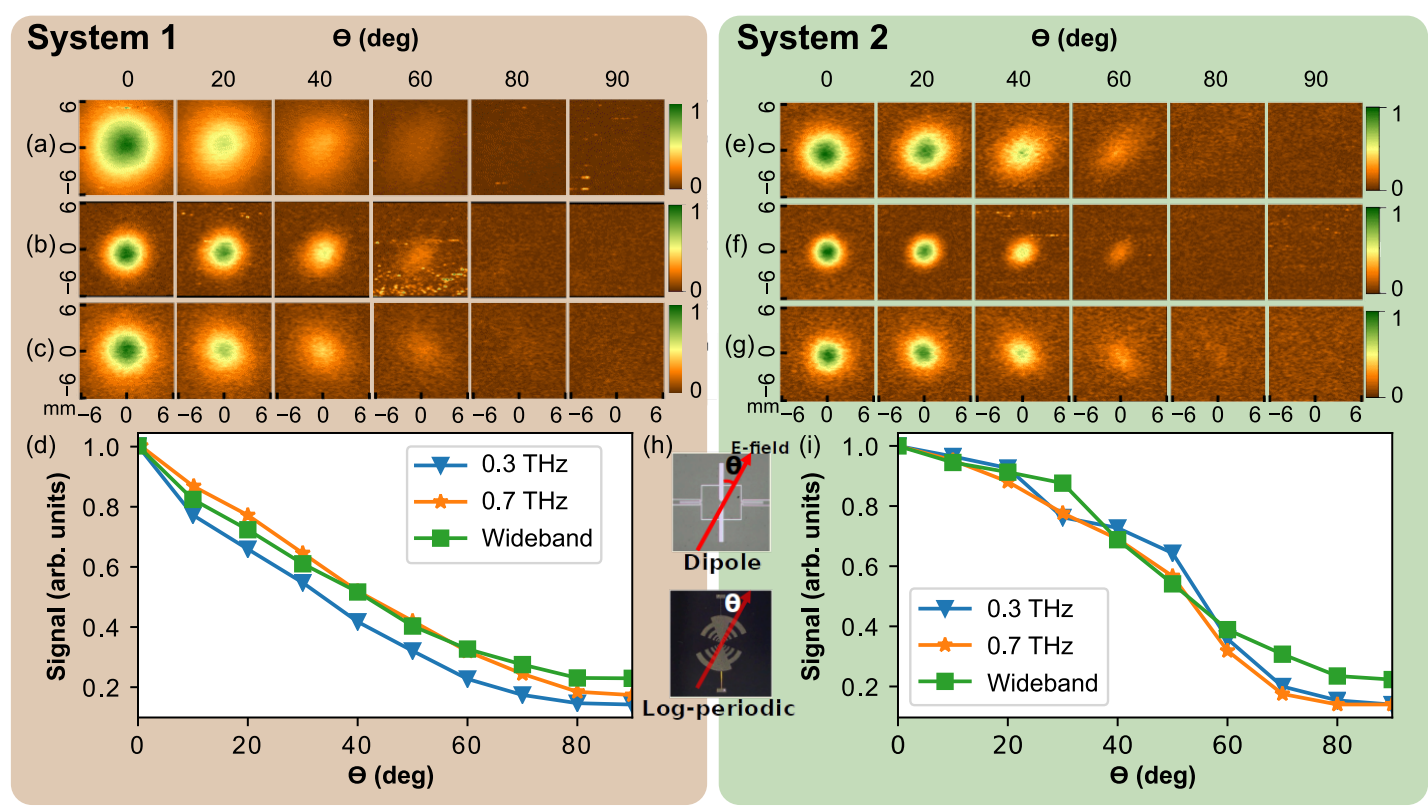

Figure 5. Polarization dependencies of the radiation patterns at various distances along the beam propagation axis recorded by different type of antenna-designs coupled Ti- $\mu$ bolometers. Panels $(\mathbf{a}, \mathbf{e})-0.3 \mathrm{THz}$; panels $(\mathbf{b}, \mathbf{f})-0.7 \mathrm{THz}$; panels $(\mathbf{c}, \mathbf{g})$-wideband Ti- $\mu$ bolometer. Panels $(\mathbf{d}, \mathbf{i})$ - the angular dependencies of the signal at the pattern center normalized to the signal at $\theta=0 \mathrm{deg}$, for System 1 and System 2, respectively. Panel (h) depicts rotation angle $\theta$ with respect to the Ti- $\mu$ bolometer axis.

\subsection{The Radiation Patterns and Spatial Mode Profiles Recorded without Collimating Optical Components}

An important concern in alignment of $\mathrm{THz}$ time-domain spectrometers is a possibility to adjust it in a convenient way without employment of focusing or collimating optics. In what follows, it is illustrated that $\mathrm{Ti}-\mu$ bolometer can successfully be used to explore radiation patterns or quality of spatial modes without hyperhemispherical lens. The spatial beam characteristics (a scan in the $x-y$ plane) recorded with $0.7 \mathrm{THz} \mathrm{Ti}-\mu$ bolometer without lens and System 1 are shown in Figure 6. As one can see, three lobes are still captured in a scanning area of $7 \times 7 \mathrm{~mm}^{2}$ although signal-to-noise ratio was about 3.3 . Careful inspection allows noting that these three constituents of the spatial mode do not diverge while going along $z$-direction indicating good alignment of the optical system. As is known, about $21 \%$ of the incident power passes through silicon lens [25], on the other hand, without the lens radiation is dispersed over the large angles, therefore, only a small fraction of the total emitted power can be registered. Despite this fact, room temperature Ti- $\mu$ bolometers sensitivity of $200 \mathrm{kV} / \mathrm{W}$ including amplification circuit and NEP of $20 \mathrm{pW} / \sqrt{\mathrm{Hz}}[23]$ is sufficient to register weak signal from photoconductive $\mathrm{THz}$ emitter even though the output beam is not effectively concentrated by the hyperhemispherical lens around the optical axis.

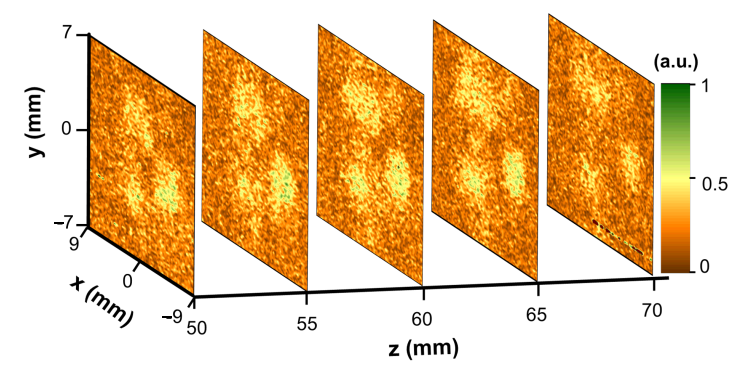

Figure 6. Spatial beam profiles of System 1 recorded by $0.7 \mathrm{THz}$ Ti- $\mu$ bolometer without collimating lens at different distances along the beam propagation direction. Note different spatial antenna modes visible along the propagation axis. 


\subsection{Time-Domain Versus Solid State-Based Solutions}

Quality of the spatial beam profile and their control as well as propagation properties of the wideband $\mathrm{THz}$ beams was one of the prime interests since invention of $\mathrm{THz}$ time-domain spectrometers. Special attention was given to an angular distribution of the radiation emitted from a terahertz antenna system equipped with a truncated spherical silicon lens [25], where $\mathrm{THz}$ pulses were recorded by moving the photoconductive antenna in space and determining the intensity of the desired frequency at every point. Despite time consuming and complex experiments, authors successfully reconstructed $\mathrm{THz}$ beam profiles and found excellent agreement with theoretical estimates. To increase the $\mathrm{THz}$ emission power, antenna-biased system were investigated [27]; to optimise spectrometer operation, practical procedures for measuring the beam quality of the wideband $\mathrm{THz}$ radiation were introduced [28]. It is worth mentioning several other experimental techniques to evaluate THz-TDS beam profiles, for instance, electro-optical sampling using non-linear crystal [29], variable size aperture scanning [30] or fixed aperture raster scanning and Hartmann test [31]. These approaches allow deeper insight in both temporal and spatial $\mathrm{THz}$ electric field evolution, as well as emission pattern determination. However, they usually suffer of either diffraction limited resolution, either extensive time requirements or low detected signal levels. For example, variable aperture scanning usually experiences edge diffraction limited spatial resolution, at small aperture diameters in particular. Moreover, it measures only the integrated spectral power and is not suitable for a study of the wideband radiation since the low frequency portion can be filtered out at small apertures. Fixed aperture raster scanning features relatively low signal-to-noise ratio; Hartmann test technique is time consuming as it requires collecting at least twice as much data as fixed aperture raster scanning [31].

In real implementation schemes of THz-TDS spectrometers or THz imaging systems, beam quality control, pattern monitoring and optical alignment require much simpler and convenient-in-use solutions. Preference to use incoherent solid-state solutions in THz-TDS beam imaging exhibits lifted diffraction and signal level restrictions, as well as reduced recording time. Moreover, the devices are compact and reliable. As elegant examples can serve employment of CMOS-based field-effect transistors for $\mathrm{THz}$ autocorrelators development [32], coupled-charge device camera to measure spot size of the $\mathrm{THz}$ pulse generated by optical rectification in a mosaic organic crystal [33] or usage of high-speed sampling coupled to CMOS devices for hyperspectral imaging in THz time-domain system [34].

The presented study demonstrates that Ti- $\mu$ bolometers can also be important part of the family bringing together solid-state-based sensors for precise and convenient incoherent validation of THz-TDS radiation patterns; it can serve for alignment aims, spatial modes quality control, for waist and divergence estimation even without additional focusing or collimating optics.

\section{Conclusions}

Lensless titanium-based antenna coupled microbolometers operating at room temperature are demonstrated for the precise monitoring of radiation pattern and spatial mode profiles control in terahertz time-domain spectroscopy systems. To provide comprehensive picture, two different THz-TDS systems and three Ti- $\mu$ bolometers with individual antenna designs-narrowband dipole antenna for $0.3 \mathrm{THz}, 0.7 \mathrm{THz}$ and a log-periodic antenna for $\mathrm{THz}$ wideband detection-are used in the investigation.The radiation patterns, spatial mode control, and explicit beam evolution along the propagation axis were examined, polarization-sensitive properties were revealed under different $\mathrm{THz}$ emitter power range. To illustrate the beam quality control, the beam waist of $1.52 \mathrm{~mm}$ and divergence of $0.045 \mathrm{rad}$ were estimated from the far-field measurements at $0.7 \mathrm{THz}$. It was shown that the Ti- $\mu$ bolometers exhibiting room temperature sensitivity values of $200 \mathrm{kV} / \mathrm{W}$, noiseequivalent power of $20 \mathrm{pW} / \sqrt{\mathrm{Hz}}$, and the response time in the $5 \mu$ s range are sensitive and fast enough to monitor precisely coherent $\mathrm{THz}$ emitters in optoelectronic time-domain systems even without any focusing and collimating optics elements. 
Author Contributions: Conceptualization, G.V.; methodology, L.M., A.U., A.Š., I.K., G.V.; validation, J.T.; sensors development, J.T., A.Š.; investigation, L.Q., L.M., I.G.; formal analysis, G.V., L.M., I.G.; writing—original draft preparation, L.Q., I.G.; writing—review and editing, G.V., L.M., A.U., I.K., J.T.; visualization, L.Q., L.M., I.G.; supervision, G.V. All authors have read and agreed to the published version of the manuscript.

Funding: This research received no external funding.

Institutional Review Board Statement: Not applicable.

Informed Consent Statement: Not applicable.

Data Availability Statement: Not applicable.

Acknowledgments: The authors would like to express sincere appreciations to Rimvydas Venckevičius and Ramūnas Adomavičius for the initial phase of the experiments; Arūnas Krotkus and Agnieszka Siemion for enlightening discussions. Special thanks goes to Aleksander Sešek for activities in Ti- $\mu$ bolometers preparation, to Kęstutis Ikamas and Daniil Pashnev for the kind assistance in evaluating spectral features of the device and to Domas Jokubauskis for his contribution in overcoming optical alignment issues in $\mathrm{THz}$ time-domain spectrometer.

Conflicts of Interest: The authors declare no conflict of interest.

$\begin{aligned} & \text { Abbreviations } \\ & \text { The following }\end{aligned}$
$\begin{array}{ll}\text { THz } & \text { Terahertz } \\ \text { THz-TDS } & \text { Terahertz time-domain spectroscopy } \\ \mu \text { bolometers } & \text { microbolometers } \\ \text { LT-GaAs } & \text { Low temperture gallium arsenide } \\ \text { Ti } & \text { Titanium } \\ \text { NEP } & \text { Noise Equivalent Power }\end{array}$

\section{References}

1. Cheung, K.; Auston, D. A novel technique for measuring far-infrared absorption and dispersion. Infrared Phys. 1986, $26,23-27$. [CrossRef]

2. Neu, J.; Schmuttenmaer, C.A. Tutorial: An introduction to terahertz time domain spectroscopy (THz-TDS). J. Appl. Phys. 2018, 124. [CrossRef]

3. Abina, A.; Puc, U.; Jeglič, A.; Zidanšek, A. Structural characterization of thermal building insulation materials using terahertz spectroscopy and terahertz pulsed imaging. NDT E Int. 2016, 77, 11-18. [CrossRef]

4. Xie, L.; Yao, Y.; Ying, Y. The application of terahertz spectroscopy to protein detection: A review. Appl. Spectrosc. Rev. 2014, 49, 448-461. [CrossRef]

5. Son, J.H.; Oh, S.J.; Cheon, H. Potential clinical applications of terahertz radiation. J. Appl. Phys. 2019, 125. [CrossRef]

6. Sun, Q.; He, Y.; Liu, K.; Fan, S.; Parrott, E.P.; Pickwell-MacPherson, E. Recent advances in terahertz technology for biomedical applications. Quant. Imaging Med. Surg. 2017, 7, 345-355. [CrossRef]

7. Trofimov, V.A.; Varentsova, S.A. A possible way for the detection and identification of dangerous substances in ternary mixtures using thz pulsed spectroscopy. Sensors 2019, 19, 2365. [CrossRef] [PubMed]

8. Puc, U.; Abina, A.; Rutar, M.; Zidanšek, A.; Jeglič, A.; Valušis, G. Terahertz spectroscopic identification of explosive and drug simulants concealed by various hiding techniques. Appl. Opt. 2015, 54, 4495. [CrossRef]

9. Miyagawa, K.; Nagai, M.; Yamashita, G.; Ashida, M.; Kim, C.; Akiyama, H.; Kanemitsu, Y. Quantitative monitoring of the internal field in the depletion layer of a GaAs-based solar cell with terahertz radiation. Appl. Phys. Lett. 2018, 113. [CrossRef]

10. Minkevičius, L.; Suzanovičiene, R.; Balakauskas, S.; Molis, G.; Krotkus, A.; Valušis, G.; Tamošiunas, V. Detection of tab wire soldering defects on silicon solar cells using terahertz time-domain spectroscopy. Electron. Lett. 2012, 48, 932-934. [CrossRef]

11. Afsah-Hejri, L.; Hajeb, P.; Ara, P.; Ehsani, R.J. A Comprehensive Review on Food Applications of Terahertz Spectroscopy and Imaging. Compr. Rev. Food Sci. Food Saf. 2019, 18, 1563-1621. [CrossRef]

12. Karaliūnas, M.; Nasser, K.E.; Urbanowicz, A.; Kašalynas, I.; Bražinskienè, D.; Asadauskas, S.; Valušis, G. Non-destructive inspection of food and technical oils by terahertz spectroscopy. Sci. Rep. 2018, 8, 18025. [CrossRef] [PubMed]

13. Wan, M.; Healy, J.J.; Sheridan, J.T. Terahertz phase imaging and biomedical applications. Opt. Laser Technol. 2020, 122, 105859. [CrossRef]

14. Aghamiri, N.A.; Huth, F.; Huber, A.J.; Fali, A.; Hillenbrand, R.; Abate, Y. Hyperspectral time-domain terahertz nano-imaging. Opt. Express 2019, 27, 24231-24242. [CrossRef] [PubMed] 
15. Puc, U.; Abina, A.; Jeglič, A.; Zidanšek, A.; Kašalynas, I.; Venckevičius, R.; Valušis, G. Spectroscopic Analysis of Melatonin in the Terahertz Frequency Range. Sensors 2018, 18, 4098. [CrossRef]

16. Kašalynas, I.; Venckevičius, R.; Tumonis, L.; Voisiat, B.; Seliuta, D.; Valušis, G.; Račiukaitis, G. Reflective terahertz imaging with the TEM01 mode laser beam. Appl. Opt. 2013, 52, 5640-5644. [CrossRef]

17. Minkevičius, L.; Jokubauskis, D.; Kašalynas, I.; Orlov, S.; Urbas, A.; Valušis, G. Bessel terahertz imaging with enhanced contrast realized by silicon multi-phase diffractive optics. Opt. Express 2019, 27, 36358. [CrossRef]

18. Jokubauskis, D.; Minkevičius, L.; Karaliūnas, M.; Indrišiūnas, S.; Kašalynas, I.; Račiukaitis, G.; Valušis, G. Fibonacci terahertz imaging by silicon diffractive optics. Opt. Lett. 2018, 43, 2795. [CrossRef]

19. Oden, J.; Meilhan, J.; Lalanne-Dera, J.; Roux, J.F.; Garet, F.; Coutaz, J.L.; Simoens, F. Imaging of broadband terahertz beams using an array of antenna-coupled microbolometers operating at room temperature. Opt. Express 2013, 21, 4817-4825. [CrossRef]

20. Oda, N. Détecteur matriciel de type bolométrique à température ambiante et camera vidéo pour l'imagerie térahertz. Comptes Rendus Phys. 2010, 11, 496-509. [CrossRef]

21. Trontelj, J.; Sešek, A. Electronic terahertz imaging for security applications. Terahertz Rf Millimeter-Submillimeter-Wave Technol. Appl. IX 2016, 9747, 974713. [CrossRef]

22. Kašalynas, I.; Venckevičius, R.; Minkevičius, L.; Sešek, A.; Wahaia, F.; Tamošiūnas, V.; Voisiat, B.; Seliuta, D.; Valušis, G.; Švigelj, A.; Trontelj, J. Spectroscopic terahertz imaging at room temperature employing microbolometer terahertz sensors and its application to the study of carcinoma tissues. Sensors 2016, 16, 432. [CrossRef]

23. Minkevičius, L.; Qi, L.; Siemion, A.; Jokubauskis, D.; Sešek, A.; Švigelj, A.; Trontelj, J.; Seliuta, D.; Kašalynas, I.; Valušis, G. Titanium-based microbolometers: Control of spatial profile of terahertz emission in weak power sources. Appl. Sci. 2020, 10, 3400. [CrossRef]

24. Sešek, A.; Kašalynas, I.; Žemva, A.; Trontelj, J. Antenna-coupled Ti-microbolometers for High-sensitivity Terahertz Imaging. Sens. Actuators A Phys. 2017, 268, 133-140. [CrossRef]

25. Jepsen, P.U.; Keiding, S.R. Radiation patterns from lens-coupled terahertz antennas. Opt. Lett. 1995, 20, 807-809. [CrossRef]

26. Van Rudd, J.; Johnson, J.L.; Mittleman, D.M. Cross-polarized angular emission patterns from lens-coupled terahertz antennas. J. Opt. Soc. Am. B 2001, 18, 1524. [CrossRef]

27. Jepsen, P.U.; Jacobsen, R.H.; Keiding, S.R. Generation and detection of terahertz pulses from biased semiconductor antennas. J. Opt. Soc. Am. B 1996, 13, 2424. [CrossRef]

28. Bitman, A.; Lumer, Y.; Moshe, I.; Zalevsky, Z. Characterization of spectrally broadband terahertz beam propagation. J. Opt. Soc. Am. B 2012, 29, 1436. [CrossRef]

29. Gürtler, A.; Winnewisser, C.; Helm, H.; Uhd Jepsen, P. Terahertz pulse propagation in the near field and the far field. J. Opt. Soc. Am. A 2000, 17, 74. [CrossRef]

30. Molloy, J.F.; Naftaly, M.; Dudley, R.A. Characterisation of Terahertz Beam Profile and Propagation through Complex Quasi-Optic Systems. Int. J. Terahertz Sci. Technol. 2011, 4, 99-103. [CrossRef]

31. Molloy, J.F.; Naftaly, M.; Dudley, R.A. Characterization of Terahertz Beam Profile and Propagation. IEEE J. Sel. Top. Quantum Electron. 2013, 19, 8401508. [CrossRef]

32. Ikamas, K.; Nevinskas, I.; Krotkus, A.; Lisauskas, A. Silicon field effect transistor as the nonlinear detector for terahertz autocorellators. Sensors 2018, 18, 3735. [CrossRef]

33. Chefonov, O.V.; Ovchinnikov, A.V.; Agranat, M.B.; Stepanov, A.N. Terahertz beam spot size measurements by a CCD camera. Opt. Lett. 2019, 44, 4099. [CrossRef]

34. Tsubouchi, M.; Nagashima, K. High-speed terahertz color imaging using a $100 \mathrm{kHz}$ line scan camera. Opt. Express 2020, $28,17820$. [CrossRef] 